\title{
ENTREVISTA
}

\section{Masonerías, intervencionismo y nacionalismo en México. De la segunda mitad del siglo XIX a los primeros años del XX}

El investigador Carlos Francisco Martínez Moreno ha defendido una Tesis para optar por el Grado de Doctor en Historia, cuyo título es "Masonerías, intervencionismo y nacionalismo en México. De la segunda mitad del siglo XIX a los primeros años del XX", en la Universidad Nacional Autónoma de México UNAM, en México, el 18 de marzo de 2016, bajo la dirección de la Dra. Virginia Guedea Rincón Gallardo y los cotutores: Dr. Silvestre Villegas Revueltas y Dr. José Antonio Ferrer Benimeli ${ }^{1}$. Carlos Francisco Martínez Moreno nació en 1973 en la Ciudad de México.

El autor nos ha concedido la siguiente entrevista.

¿Cuáles fueron los motivos que le llevaron a enfocar su investigación hacia la Masonería?

Contribuir a llenar un vacío señalado en simposios internacionales durante varios años, sobre las dimensiones social y política de la masonería en México de la segunda mitad del siglo XIX a los primeros años del XX, así como ampliar el período temporal hasta finales del régimen del presidente de la República Porfirio Díaz, para ir más allá de la línea de investigación que desarrollé en la maestría.

\section{¿Cuáles fueron las fuentes que ha utilizado?}

Las más importantes fueron manuscritos de intercambio epistolar y documentos inéditos, que resguardan archivos masónicos de: México, Inglaterra, Francia, España, Cuba, Estados Unidos, Colombia y Costa Rica.

\section{¿Cuáles fueron las principales dificultades con las que se ha encontrado? ¿Cómo las ha superado?}

Para acceder a las fuentes en el extranjero, sin las cuáles la tesis no podía haberse realizado, la principal dificultad fue el financiamiento para realizar estancias de investigación en los archivos; para esas actividades conté con el apoyo del Consejo Nacional de Ciencia y Tecnología CONACyT y de la Universidad Nacional Autónoma de México UNAM, si bien

\footnotetext{
${ }^{1}$ La tesis está disponible en la siguiente dirección: http://132.248.9.195/ptd2016/marzo/507007586/Index.html
} 
la mayor parte de los recursos necesarios los obtuve de préstamos bancarios que consideré una inversión a largo plazo.

Otro problema, de índole hermenéutica, derivó de los contenidos de fuentes no masónicas, especialmente de la prensa porque no siempre fueron confiables, debido a que eran usados como "arma" ideológica de propaganda para crear imaginarios colectivos usados para presionar a favor o en contra de algún grupo, clerical, masónico, político, económico, nacional o extranjero; no obstante, con la debida interpretación del contexto en el que aparecían, fue posible comprobar que el tratamiento de los hechos representó un marcador para identificar lealtades, alianzas, complicidades, enemistades, oposiciones y traiciones; además, su análisis permitió advertir que algunos eventos relevantes entre los masones no siempre fueron registrados en el discurso periodístico, que pese a su trascendencia en ocasiones fueron omitidos y, cuando ello ocurrió, fue posible identificarlo "cruzando" información con el análisis de las fuentes masónicas directas.

Un obstáculo más consistió en validar la filiación masónica de los individuos estudiados. En general las listas localizadas sólo contenían nombres de los dirigentes de los grupos y no de todos sus miembros. En otras no se explicitaba el rito que practicaban ni el grado $\mathrm{y}$, en los casos menos útiles, sólo se enunciaban los nombres sin más datos. Al principio se pensó crear largas listas de anexos, en su lugar se prefirió integrarlos en pocas tablas y, para aquellos que participaron en la política gubernamental, se optó por elaborar mapas con información cualitativa y cuantitativa.

Aparte, fue necesario superar el trato hagiográfico de la historiografía masónica, principalmente de una corriente que se reputaba como regular e insistía que los masones en México corrompieron su tradición al no cumplir con sus cánones y tornarla nacionalista, patriótica, política y, por tanto, espuria e irregular; para ello, se pudo mostrar que la causa fue la convicción de que no hacerlo así ponía en riesgo la gobernabilidad del país o amenazaba la soberanía nacional, y se encontró que la postura masónica canónica de los masones regulares no era "apolítica" como ellos sostenían, sino una ideología política encubierta que se usó para desmantelar redes de elites nacionalistas en el poder, para operar políticamente bajo la apariencia de que sólo practicaban la masonería regular.

Esto último representó un problema epistemológico, porque los grupos "regulares" se apoyaban en un discurso que no soportó el análisis de sus bases, por resultar falaces y con base en ellas juzgaban que lo que no se adecuaba a su paradigma no era masónico y sí irregular. Pero el examen de sus presupuestos permitió mostrar que no sólo se trataba de imprecisiones sino de mitos creados y transformados a modo para legitimar a su grupo y excluir a otros; al respecto se buscó contribuir a su comprensión para identificar cómo y con qué finalidad fueron usados contra los que combatieron y rechazaron como irregulares. 


\section{¿Cuáles fueron las principales problemáticas históricas que su trabajo ha resuelto?}

Contribuyó a llenar el vacío que provocaba la ausencia de estudios que explicaran las dimensiones social y política de la masonería en México para el período estudiado, señalado en simposios internacionales durante varios años; con un análisis desarrollado a lo largo de cinco capítulos, se buscó resolver problemáticas históricas sobre: el perfil de los masones, sus normas, sus organizaciones, ideologías y sus contextos políticos, el conflicto con el clero por la intervención del Papa contra la soberanía nacional, el liberalismo y la laicidad, las disputas masónicas, la opinión de la prensa y el impacto geopolítico de los gobernadores masones. Lo anterior con el apoyo de: gráficas, tablas y más de 40 mapas de elaboración propia, que permiten evidenciar las redes masónicas entre 1845 y 1912.

\section{¿Por favor, podría resumir la esencia de su Tesis en dos líneas?}

Analiza la implantación y la expansión del Rito Escocés en México, y muestra la dicotomía entre la masonería impuesta desde el extranjero, que se decía regular y apolítica, y otra nacionalista.

\section{¿Cuáles fueron las lecciones, a todos los niveles, personal y profesional, que usted ha deducido de su experiencia investigativa?}

En lo profesional fue muy enriquecedor integrar las observaciones que recibí de la directora de la tesis, la Dra. Virginia Guedea Rincón Gallardo, de los cotutores, el Dr. Silvestre Villegas Revueltas y el Dr. José Antonio Ferrer Benimeli, y de las sinodales, la Dra. María del Refugio González Domínguez y la Dra. Lucrecia Infante Vargas, porque al atender exigencias de investigadores con especialidades tan diferentes, me obligó a indagar sobre varios ejes de análisis que complementaron mi formación.

En lo personal, aprendí que la investigación doctoral requirió reorientar las prioridades de mi proyecto de vida, y a persistir y a sobreponerme al desaliento en momentos difíciles que implicaron sacrificios, renuncias y pérdidas, y que todo el esfuerzo cobró sentido al final, ahora que me ha permitido contribuir a formar nuevas generaciones de especialistas en el tema.

\section{¿Ahora, cuáles son sus proyectos profesionales?}

Mi proyecto profesional vinculado al tema de la masonería consiste en formar especialistas en su estudio, para ello, continuaré impartiendo la cátedra de Historia de la Masonería en México en la Facultad de Filosofía y Letras de la Universidad Nacional Autónoma de México UNAM, que desde agosto de 2015 autorizó impartir, y buscaré que este proyecto 
precursor en el país se replique en otras universidades.

¿Quisiera destacar algún aspecto que no se ha contemplado y que usted consideraría digno de reseñar?

Solo reiterar que, a partir del análisis de la dicotomía entre las dos posturas masónicas, la vertiente que desde el extranjero se impuso, y que se decía regular y apolítica, y la contraria que fue nacionalista; pudo demostrarse que la primera fue intervencionista, política y anti nacionalista, y que por ello fue combatida por otra con compromiso social, que fue desprestigiada como irregular; y tras el estudio quedó claro, que la tradición regular fue irrelevante e incluso retardataria y pro esclavista, y que la calificada de irregular fue más humanista, progresista e importante por lo que aportó a la sociedad mexicana, lo que es de suponerse que también pudo ocurrir en otros países, lo que corresponderá a otros colegas indagar.

Esta entrevista se efectúo de forma telemática el 25 de marzo de 2016.

Autores de la entrevista: Ricardo Martínez Esquivel e Yván Pozuelo Andrés, Director y Editor de REHMLAC+.

DOI: http://dx.doi.org/10.15517/rehmlac.v8i2.27245 